\title{
日本前資本主義社会形態についての一考察 \\ 一日本封建制度の特徵と発展軌跡一 \\ On the Pre-capital Social System of Japan - \\ The features and development Track of Feudal System \\ in Japan
}

\section{贾 华 \\ 深圳职业技术学院}

\section{要旨}

近代、アジアではどの国よりも先に独立資本主義社会システムになったのは日本であった。それ は1868年の明治維新運動及び当時の国際情勢に推し進められる要素のほか、日本社会の奥に積 み蓄えてきた政治、経済、文化諸構造にある要因によるが、その最たるものは歴史的動因ではない かと思う。十二世紀に現われた藩制経済を主体とする日本封建制度はすでに“アジア式産業様式” のパターンから脱していた。そういう西ヨーロッパのような社会システムが凡そ日本封建制度に発 展勢力を制約されていた。例えば土地帰属が割合固定的で、地方分権の伝統はあるが、自耕農民と 市民階層の現われ、マーケットの早期発育などが起こっていたのである。明治維新運動は日本の近 代史上、意義のある画期的な大事件に違いない。すなわち、その維新運動により徳川幕府という封 建幕藩体制が倒され、近代的な天皇支配というブルジョア独裁政治体制が成りうると共に、政治、 経済、社会一連の改革が行われた。これら一連の改勒日本資本主義の発展に拍車をかけたのであ る。本研究の目的はマクロ的には日本のその独立した資本主義社会形態が成立した歴史進展のポイ ントを把握し、日本資本主義社会システムの発展が偶然ではないことを明確にさせることである。

\section{内容提要}

近代日本是亚洲唯一步入资本主义社会的国家。1868 年的明治维新建立了近代天皇制资产阶级专 政政体, 进行了一系列政治、经济及社会改革, 加速了日本社会资本主义的进程。但日本近代资本主 义的出现并不是偶发的社会现象, 其历史动因长期蕴涵于日本封建社会内部政治、经济以及文化诸多 构造之中。本文拟从宏观上阐述日本封建制社会形态的历史演进, 说明日本近代资本主义的形成是其 历史发展合乎逻辑的结果。

\section{关键词:}

日本 封建制度 荘園領主権制度 近代資本主義 


\section{日本前資本主義社会形態についての一考察 \\ 一日本封建制度の特徵と発展軌跡一}

\section{贾 华 \\ 深圳职业技术学院}

近代日本是亚洲唯一步入资本主义社会形态的国家。1 868 年明治维新推翻了德川幕府封建幕藩体 制, 建立了近代天皇制资产阶级专政政体, 进行了一系列政治、经济及社会改革, 加速了日本社会资 本主义的发展。但是, 我们不能将日本近代资本主义的发生与发展简单归结为明治维新的社会变革效 应, 日本近代资本主义的出现并不是偶然的社会现象, 其历史动因长期蕴涵于日本封建社会内部政 治、经济以及文化诸多构造之中, 是日本历史发展合乎逻辑的结果。那么, 如何看待日本明治维新以 前的社会形态, 为什么日本的封建制能顺利生长出资本主义诸因素并进而较为迅速地进入资本主义阶 段, 本文试图从宏观的角度来阐述这一历史演进的轨迹。

\section{1. 日本的早期封建制}

封建” 的概念是历史地发展变化着的, 我们不能用凝固不变的观点看待它。对 “封建”一词, 中 国古代固有的意思是中央集权下的 “封邦建国” , 是天子将天下分封给诸侯并设立郡县。日本国内对 “封建”的含义在不同时期有不同的解释。自大化革新（公元 645 年）实施班田收授法以及统一租、 庸、调赋税制度以后, 日本基本完成了以公地公民制为基础的中央集权体制, 已形成了一个形态完整 的东方早期封建社会, 但查阅日本最具权威性的国语大辞典 (小学馆) 等学术资料都认定日本的封建 制始自镰仓幕府时代。从日本学术界对 “封建” 的解释看, 公地公民制这种土地国有制属于一种古代 国家的政治形态, 不承认它的封建性质, 封建制的唯一标志应该是土地私有制。

日本在大化革新前社会生产力何不发达, 共同体氏族社会内部的地域性给统一国家的建立带来很 大困难。在这种情况下, 日本统治者开始仿效中国唐朝的律令制。大化革新的新政否定皇室、豪族的 氏性体制, 确立地方行政, 建立了中央集权的国家制度, 同时改革土地制度, 废除氏族社会土地私有 制, 确立了早期封建经济以 “公地公民”为基础的土地国有制, 在此基础上制定户籍记账制, 实施了 班田收授法 (即班田制) 及统一租、庸、调税赋制度。从这个意义上讲日本已具有东方早期封建土地 所有制的性质, 但我们必须注意到 8 世纪中叶以后日本封建土地所有制在形态上发生的重大变化。日 本在班田制瓦解后, 继之出现的并不是中国的地主土地所有制, 而是庄园领主制。这一时期的日本一 反亚细亚社会发展形态, 出现了许多西欧封建土地所有制的因素。这是一个意义重大的历史现象, 日 本庄园领主制的出现对日本整个封建时期的土地所有制及社会发展都产生了决定性的影响。

庄园领主制之所以在日本出现, 我们从日本社会发展的内部基因中寻找原因。日本位于东方边 
陣, 是个岛国, 国土被山、川、湖、海分割, 形成了许多小块的相对封闭的村落社会, 即一个个相对 独立的生活共同体。这种村落社会在史前不是行政意义上的单位, 它只是一种生活资料及生产资料能 达到自给自足的人类群体。日本进入阶级社会比较晚 (公元 3 世纪至 4 世纪), 原始社会以血缘为纽 带的氏族集团不是随着共同体社会内部生产力的发展、私有制的出现而逐渐为阶级所取代, 日本原始 社会是在中国先进文化的冲击下解体的。氏族血缘关系也没有经历希腊、罗马那样由家族奴隶制转为 劳动奴隶制而导致氏族血缘关系解体的过程。同时又因婚姻财产继承关系不同于中国, 家族内的血缘 关系淡薄, 也没有形成象中国那样由氏族血缘纽带联系起来的宗法制社会结构。大化革新后, 虽然引 进了律令制度, 实行了公地公民制, 但地域共同体的文化形态仍然存续着, 共同体内部的氏族体制并 未消失。因此, 大化革新所建立的中央集权统治与中国隋唐相比其集权性要相差许多。加之革新后地 方官吏多由原来的氏姓贵族、国造、县主、稻置世袭, 这些豪族在革新前就拥有大量部曲、部民, 大 化革新后他们摇身一变成为国司、郡司, 实际上掌握着地方的军事、司法、行政大权。这些豪族对中 央政府由来已久的离心力日益增强, 班田制盛行时高官豪族们就保有“位田”、“职田”等私有土 地, 班田制废弛时这些土地就完全成了他们名下的私田。随着时间的推移, 贵族、寺院、地方豪族的 开垦热版演版烈, 有权势者还占据了面积巨大的山林、平原, 普通农民更无地可耕, 庄园出现的同时 农民也沦为庄园农奴了。

自从 8 世纪中叶庄园领主土地所有制的嚾形出现, 日本实际上走了一条不同于中国的发展道路。 虽然从广义上讲同属封建时代, 但中国从唐朝到清朝一直继续着中央集权君主制国家的政治制度, 而 日本则逐渐形成了封建分权制政治格局。正是由于这种具体形态上的差异, 自平安时代中叶开始, 日 本停止派出遣唐使, 虽然之后与中国文化上的联系仍在继续, 但已经不再从中国学习或移植政治制度 方面的做法了。

\section{2. 日本的庄园领主制}

8 世纪中叶, 班田制下的日本农民不堪繁重的租税徭役, 抛弃户籍和口分田, 纷纷逃往他乡。贵族 和官吏营私舞弊, 利用掌管班田之权大肆兼并土地, 使口分田日益缺乏。大化革新所建立的班田制到 9 世纪已趋于势微, 国家为推行班田制所必须的土地版益不足, 租、庸、调的赋税制只剩下 “租” 这一 项了。

在日本班田制渐趋瓦解的过程中, 出现了庄园。日本庄园最早出现在何时, 目前学术界何未定 论, 但可肯定的是庄园源于日本的土地私有。私有土地早在班田制实行期间就已存在, 最具代表性的 是王公贵族、神社、佛寺等特权阶级占有的职田、位田、功田、赐田、神田、寺田等, 表面上属于国 家, 实际上这些田除职田外, 基本上可以世袭, 而且在剥剮方式上比班田更为灵活。8 世纪初, 日本政 府为增加耕地, 多次颁布法令, 如《三世一身法》 (公元 723 年) (注 1) 、 《旺田永世私财法》(公 元 743 年) (注 2 ) 等, 鼓励民间垦田并承认旺田私有。于是有势力的贵族、地方豪族、寺社均利用此 
令积极旺田, 扩大领土, 设置庄园, 史称旺田型庄园, 成为国有土地私有化的契机。进入 9 世纪后, 以权门势家、寺社为中心, 通过购买、兼并等形式, 庄园进一步得到了发展。

随着大土地私有制的发展, 律令制的公地公民原则日益受到破坏。到平安中期 (10 世纪), 出现了 一种新的献地型庄园, 并逐渐取代垦田型庄园成为中世庄园的基本形态。

10 世纪以后, 领主具有奴隶制色彩的直营地（称为 “佃”) 几乎全部租佃给无地公民。这些佃农 (称为 “田堵” ) 由于增强了对土地的耕作权, 改变了早期庄园中农奴仅是土地耕作者的状态, 出现 了以 “名主” 经营 “名田” 这一新的庄园形式。日本的早期庄园虽为地方豪族及大寺院占有, 但庄园 的领地并不是法律意义上的私有土地, 所以领主还需向国家和地方国衙上缴年贡 (地租)。不仅如 此, 国家对庄园还保有征调劳力以及检查有无非法行为的权力。因此庄园并不是行政意义上的单位, 更无司法权。10 世纪以后, 由于 “名主” 这个阶层的扩大, 生产力有了很大发展。农民对生产的关心 以及水稻插积等劳动密集型农业的特点更加强了耕作者的独立性, 土地与农民的结合程度得到了提 高。这样就出现了家庭类型的农户, 农民已从原来的国家奴隶形态逐渐过渡到庄园农奴（庄民）形态 了。

一般庄园每年都要向朝廷输纳年贡, 起初只有寺田、神田等拥有不纳租税的特权, 后来王公贵族 利用他们手中的地位和权力, 以种种借口要求朝廷允许他们不纳税。于是, 与 “名主” 阶层出现的同 时, 中央大贵族的庄园获得了 “不输不入” 的特权 (注 3), 统称为 “不输不入庄园” 。这样, 地方 豪族为了摆脫政府的控制, 谋取逃避课役, 求得贵族的庇护, 把土地所有权名义上寄进 (捐献) 给中央 豪族或寺社并交纳一定年贡, 然后接受这种名义上的领主（称为领家、本所）的任命, 以庄官（庄园 管理者) 的身份继续管理庄园, 掌握庄园的实际领主权, 并向国家申请 “不输” “不入”的特权。结 果就形成了名主、庄官以及接受寄进的领家、本所 (后二者为公家) 这样一个权力系统。名主这个阶 层中既有自营小农也有拥有较多耕地并役使 “下人” 的奴隶主。此外还有将部分土地租佃给自营小农 耕作以索取实物地租者。因此, 除去最下层的佃农, 名主与本所、领家及庄官的关系已不单纯是奴 隶与奴隶主的关系, 事实上有些名主还成了庄园中农村共同体的首领, 直接参与对下层广大农民的剥 刿。

日本的封建制自镰仓幕府建立曾有一段相当稳定发展的时期, 镰仓体制是在庄园领主制经济基础 上建立起来的。一方面,追随源赖朝的多是中、下层庄园领主, 另一方面, 为源赖朝建功立业效命的 “御 家人”（注 4) 得到的回报也是封建庄园。镰仓初期, 仍旧延续了平安时代的古代庄园制, 一个庄园由 数个 “名田” 组成, 名主从庄园领主处获得名田的私有权, 进行自主经营。镰仓中期后, 开始有了显 著变化。庄园内的大名主、土豪成为幕府的地头。他们依仗幕府的势力, 代表庄园领主管理庄园, 每 年向领主缴纳一定的年贡和租税, 这种形式称为 “地头请所” 。以后又出现了 “下地中分” 的经营方 式, 把庄园耕地和庄内农民分为 “地头分” 和 “领家分”, 地头断绝了与领家的一切关系, 完全独立 于领家。通过 “地头请所” 和 “下地中分” 这两种方式, 地头逐渐转化为在地领主。镰仓后期, 庄园 
领主把一部分实物地租 (稻谷) 通过商人卖给地方市场, 以货币代替实物地租, 促进了原来极不发达 的手工业和商业的发展。镰仓时代的庄园进一步巩固和发展了庄园制度, 成为镰仓幕府封建经济的基 础。

日本的封建土地国有制趋于崩溃, 田入私门, 到庄园制形成发展壮大经历了 300 多年。也就是从 8 世纪末各地豪强私领扩大, 9 世纪 80 年代到 11 世纪中叶藤原氏外戚贵族集团专权, 11 世纪中叶后以 上皇为中心的公卿集团得势（院政 “时期）。12 世纪中叶, 武士阶级登上政治舞台, 通过源氏与平氏 的争战, 源氏胜利并于 1192 年成立镰仓幕府。至此, 日本以庄园领主制为主要形态的封建制进入成熟 稳定期, 也就是日本史学家认定的封建制始于镰仓时代。自从镰仓幕府成立后, 日本持续了近 700 年 的武家政治（注 5), 直到 1868 年德川幕府崩溃为止。

封建庄园领主制, 是封建制的一种形式。纵观日本封建领主制发生、发展直至建立的过程, 可以总 结出它的一些基本特点, 我们例举一二。

第一, 日本庄园领主制是寄进与分封相结合的封建等级土地所有制。

日本在封建庄园领主制时代实行的封建等级土地所有制与西欧各国的封建等级土地所有制虽大体 相似, 但西欧各国的封建等级土地所有制, 一般是通过采邑分封建立起来的, 而日本的等级土地所有制, 却是循着自下而上层层寄进和自上而下层层分封两条路线形成的。这是由于日本封建等级土地所有制 形成以前, 曾存在过土地国有化的班田制。班田制的确立曾为日本生产力的发展和社会进步起过巨大作 用, 然而, 各级统治者利用班田收授的权力巧取豪夺, 竟相崖殖, 日益加重人民的负担, 开始了土地私有 化的过程。随着私有土地的发展, 各地豪族乘机兼并土地建立庄园。寄进型庄园出现后, 形成了本家一 一领家一一庄官的层层庄园领主结构。这种自下而上的层层寄进,不仅使下级领主在上级领主的庇护下 得以生存和发展, 也使上级领主恃权自肥, 相互间又都依存于国家权力, 以国家官吏的身份行使领主支配 权。日本的分封制庄园是寄进型庄园充分发展的产物。寄进型庄园的发展, 导致班田制破坏和权门势家 政治经济实力日益增强, 彼此之间为了获得更大的权力和利益展开激烈争夺。建立镰仓幕府后, 源赖朝 给关东一带的大小领主武士- - “御家人” 分授土地以形成地方政权并建立“侍所” ，“御家人”与 幕府之间形成一种“主从关系”和“恩给关系”。而“御家人”又给自己部下“家之子”“郎党”

“所从” (均为武士) 分封土地, 由此产生了幕府将军- - 御家人- - 一般武士的土地等级制度。御 家人必须在镰仓官府 “奉公” 并服军役, 以此换取对封土的领有权并作为庄官获取收益。一般武士则 要为御家人履行义务。这种封建土地所有制从形式和内容来看酷似西欧庄园领主制中国王一一各级贵 族一一骑士这一等级结构。

第二, 日本以庄园领主制为基础的封建制是 “公家”（注 6) 与 “武家”（注 7) 两种因素结合的 产物。

日本庄园领主制出现的直接历史动因在于其地域共同体的生活形态和文化形态。大化革新后虽然 实行了公地公民制, 但是地域共同体内部的氏族体制并未消失。除去中央政权周围为皇室直属领地 
外, 日本全土仍置于无数地方豪族的支配之下, 因此大化革新所建立的中央集权并不具强大的制约力 量。正是这样的政治环境孕育了公家和武家二重因素相结合的 “公武二重政权” , 形成了一个权力基 础多元化的长期格局。

在寄进型庄园出现后, 形成自下而上层层依属的封建等级土地所有制的过程,决定了封建领主上下 级之间有很强的家族制控制和依附关系, 以家族制方式筑起了幕府政治的基础一一武士集团。他们以 中央政府为靠山, 将国衙作为地方的征税机构并没收公领内名主的土地建立庄园。这时, 国司已不是 国家的行政官, 而是名为国衙领实为庄园领主的地方庄官了。至于国守等高级官吏, 他们并不到地方 上去, 只是在京城坐收自己管辖地区的年献, 具体事务都让地方豪族出身的官吏及中下级国司去做, 他们在经济上及社会上的角色已无异于民间的领主及武士化的庄官, 只是比起民间的领主庄官来占有 更多的领地和拥有更大的权威。日本历史上最大的武士团也就来自这一势力集团，如 12 世纪后出现的 平氏与源氏两大家族就是他们的代表。

从上述特点可以看出日本封建社会的基本格局, 一是当日本进入武家政治以后出现了一个权力基 础多元化的局面。因为寺院、各级贵族、武士的经济基础都是庄园领主制, 而庄园是一个个规模不等 的共同体, 庄园领主原本就是一种独立于中央集权的倾向。到了武家占统治地位以后, 各级武士的血 缘集团性和扩张性更加剧了这种倾向。另一方面, 无论是寺院、中央贵族或是武士都不能无视皇权。 虽然他们在政治、经济、军事上拥有强大的实力, 但 “君权神授” “万世一系” 的天皇中心主义仍是 日本民族长期以来的传统观念。因此, 镰仓政权的建立并没有导致日本产生西欧中世纪那样封建割据 的贵族民主制和等级君主制, 与之相反, 产生了“公武二重政权” 这一具有日本民族特点的独特政 体。

\section{3. 日本的晚期封建制}

江户时代 (即德川幕府时代) 是日本历史上最后一个封建时代。这一时代自 1603 年德川家康任征 夷大将军始至 1867 年德川庆喜向天皇奉还大政辞去将军职务止历时 265 年之久。

17 世纪以来的德川幕府体制是 13 世纪以来日本幕府封建体制的继承和发展, 在中世纪形成的庄园 领主制的村落或地域共同体到了室町时代, 特别是在战国时期以后又有了很大的发展（主要是自营小 农的大量出现和分化、战国大名的抬头、分国法的制定及社会经济的组织化）。在江户时代, 虽然领 主与土地关系不象从前那样紧密, 武士阶层也变化为管理土地的家臣, 但不仅 17 世纪以来的领主权被 继承下来, 而且社会的基本结构也几乎与 17 世纪以前相同。最主要的是, 江户时期, 随着社会财富的 积累出现了城市资产阶级。所以从某种意义上讲, 江户时期是日本早期资本主义发生、发展过程中的 重商主义时代, 也是近代国家形成的初级阶段。

江户即现在的东京, 是德川幕府的所在地, 当时已有 100 多万人口, 不仅在日本, 在全世界也是 首屈一指的大城市。江户幕府为了加强中央统辖权, 明令各藩的领主每隔一年就要到江户居住并在将 军帐下参勤, 即有名的 “参勤交替” 制度。“参勤交替” 制使各地大名必须维持两个居住地的生活开 
支, 经济上负担很重。但由于大量武士频繁往来, 交通的建设如火如茶, 形成了以江户为中心的交通 要道, 这对沟通全国各地的文化及传播当时的中央文化（江户文化）起了积极作用。江户是当时地方 武士最重要的聚集场所, 幕府的官员也经常与之往来。

武士与一般市民的交往、各地文化的交流对以后出现 “町人文化”（市民文化）起了决定性的作 用。“町人”主要是指居住在城市中的手艺人及商人, 实际是指当时新兴的一个社会阶层一一城市资 产阶级。在当时日本的大城市京都、大阪以及江户同时出现了具有这些特点的新兴市民阶层一一小资 产阶级。城市的稳定、繁荣与民间财富的积累必然会形成商业性的消费社会, 城市的生活方式与劳动 形态又给市民阶层带来了余暇, 而余暇的出现则是市民文化发展的先决条件, 所以江户时期的 “町 人”社会就是现代日本市民社会的雏形。

从世界历史的发展来看, 资本主义萌芽是在城市中出现的, 而作为一种新的生产方式及交换方式 的资本主义经济形态只能产生于城市的主角一一自由市民中间。被称为 “布尔乔亚” 的自由市民不仅 有自己的文化观念, 在经济活动中也基本确立了自己的权利观念。从西欧的历史来看, 中世纪后期 的城市大多是一个自治体, 那里有独立的司法单位和立法单位, 甚至还出现了一系列与现代社前会相 近似的民法、商法。法律秩序与民权观念这两大要素是资本主义得以发生、发展的最基本提。只有在 这样的法律和权利体系下, 资本主义经济形态才能作为一种必然的、新的生产方式出现在历史舞台 上。

16 世纪中期, 在大阪的附近就出现了一个自由城市- - 堺。与一些欧洲的自由城市一样, 堺市的 市民代表为了捍卫在行政及司法上的自治权而强化了自主防卫体系。在经济上, 堺市的商人通过当时 中国明朝与来到东南亚的欧洲人进行贸易往来而积累了巨大的财富。16 世纪的日本正处在内乱时期, 堺市的出现可谓是一个例外的现象。这个自由城市在一个世纪之后就逐渐衰落了, 但是, 这种地方自 治的精神在 16 世纪后牛叶却普及到了日本的许多城市中。

17 世纪初, 随着商业的发达, 城市日趋繁荣。幕府为制弱各地大名的反抗力量, 下令摧毁除藩主 居住地以外所有地方的城堡, 颁布了“一国一城令”。幕藩的领主将武士聚集到城堡周围, 并召集手 工业者、商人也聚集到这里, 在日本称为 “城下町”, 城下町几乎无例外地成了各个藩的经济中心, 在 “城下町” 的基础上慢慢形成城市的规模。到 17 世纪末, 日本全国上下已有城市 300 余座。明治维 新以后, 许多城下町成了各县的县厅所在地, 有影响的教育机构也大都开设在这些地方, 商业、金融 业的发展更加速了这些城下町向近代城市转化的过程。

德川中期以后商品经济得到了极大的发展, 日本全国形成了以大阪、江户、京都为中心的商品经 济圈。在江户时代中后期出现的城市手工业行会、商业机构虽有其独特的形式, 但已是一种市场经济 运行的雏形。商品经济的发展也把农民卷入了商品生产的环流, 农村不仅是商品原料的提供地, 同时 也成为简单加工业的工厂。由于城乡商品生产的流通、合作性日益加强, 打破了藩与藩的界限, 商品 生产市场日益扩大, 全国各地出现了相对独立的市场, 资本主义生产方式的萌芽逐渐出现。在德川时 
代后期不仅是江户的规模已堪称世界之最, 大阪、京都、名古屋、金泽、广岛、川内、和歌山、鹿儿 岛以及堺和长崎都发展到了相当的规模。如果与 19 世纪中期的英国都市相比较, 就可以得出结论, 当 时的日本已处于相当先进的发展阶段。

从上述可见, 17 世纪以后, 商品经济冲击着封建领主经济结构, 促进了生产关系和农村阶级的变 化, 德川幕府统治下的日本社会出现了许多早期资本主义的因素。这些因素的出现是日本历史自身发 展的结果, 它在形态上有类似西欧社会的某些方面, 但并不类同于西欧社会。此后, 在明治维新这场 自上而下的近代化运动中, 日本统治阶层明确提出了 “脫亚入欧” 的口号, 至此, 日本社会开始有意 识地引进西欧的文化科学知识乃至政治机构模式, 大大加速了日本社会的资本主义进程。

综上所述, 日本近代资本主义的出现并不是偶发性的历史现象。12 世纪出现的以庄园制经济为主 体的日本封建制已脫离了 “亚西亚生产方式” 范畴, 这一类似西欧社会的封建形态从总体上制约了日 本封建制的发展趋向。虽然领主制经济和中国的地主制经济都是以土地及其他生产资料私有制为基 础, 都有可能将生产资料、生活资料转化为资本而出现资本主义, 但由于庄园领主制比起地主制来其 主要生产资料一一土地的归属更为稳定, 所以生产力的发展较为迅速, 以至建立在这一经济形态上的 封建制能在较短时间内培育出它的掘墓人, 即自耕农和市民阶层。日本进入中世纪以后, 其庄园领主 制相对稳定, 土地不能随意买卖和分割, 这无疑对生产力的发展是极为有利的因素。而且, “公武二 重体制” 的政权形态使日本出现了地方分权的政治格局, 这种格局对于地方经济的发展产生了积极作 用，促进了市场的早期发育。诸多的历史动因促使日本虽然远离西欧，但其封建制发展进程却出现了 与西欧相似的因素。在曾经辉煌的 “亚西亚生产方式” 到了近代逐渐衰退的情况下, 地处东亚边陲的 日本却作为唯一的例外步入资本主义社会形态。日本近代资本主义的出现是明治维新在日本近代史上 所起的重大作用, 是当时国际政治形势给日本带来的巨大机遇, 更是日本历史发展演变合乎逻辑的结 果。

\section{注释}

（1）承认被开垦的土地三代之内为私有, 规定开垦生荒地 (从未开旺过的土地) 可传三世后归公, 开垦 熟荒地（已开垦又荒芜的土地）可享用一生。

(2) 承认依照位阶将部分开垦地改为永远私有。

（3）“不输” 即国家授受的征租权; “不入” 即拒绝国家派遣的检田使等官吏进入其庄园, 排除国家 行政机关对庄园事物的干涉。

(4) 与源赖朝有主从关系的地方土豪、武士。

(5) 即幕府将军掌握实权。

（6）指天皇、朝廷, 即中央政权。

（7）指武士阶层，镰仓幕府建立后也指将军及将军帐下的武士团。 


\section{参考文献:}

浙江大学日本文化研究所编著 日本历史 高等教育出版社 2007

吴之桐 从中日法文化的历时性比较看日本文化的基本结构. 东北亚论坛 2003（4）

贾 华 双重结构的日本文化 中山大学出版社 2010

石田一良 日本文化史概论 吉川弘文馆 1987

小野武夫 日本庄园制史论 有斐阁 1943

荒居英次 日本史诸问题 文化书房博文社 1980 